\title{
Percepção dos familiares de pessoas com esquizofrenia acerca da doença
}

\author{
Perception of schizophrenic's relatives about disease
}

\author{
Percepción de familiares de esquizofrénicos sobre la enfermedad
}

\begin{abstract}
Fernanda Matos Fernandes Castelo Branco ${ }^{1 *}$, Juliana Baia da Silva1 ${ }^{1}$, Carlos Manuel Sanchez Dutok ${ }^{1}$ Tancredo Castelo Branco Neto ${ }^{1}$.
\end{abstract}

\section{RESUMO}

Objetivo: descrever a percepção dos familiares de pessoas com esquizofrenia acerca da doença. Metodologia: estudo descritivo de abordagem qualitativa, realizado com cinco familiares de pessoas com esquizofrenia no município de Oiapoque. Para a produção dos dados utilizou-se entrevista semiestruturada, no domicílio dos familiares, e dados analisado foram analisados pelo software Iramuteq. Resultados: são apresentados a análise de similitude e as seis classes geradas a partir das percepções dos familiares: Vivência com o paciente, Rotina de casa, Rotina médica, Interação familiar, Realidades dos sintomas e Interação familiar. Considerações finais: Os resultados mostraram que as percepções são permeadas por sentimentos de desvalia, tais como: frustrações, sofrimentos, prejuízos na qualidade de vida e fatores nos quais dificultam o convívio familiar, pois, há dificuldade em associar e entender os comportamentos resultantes da doença, porém a preocupação do cuidar é a mesma.

Palavras-chave: Percepção, Esquizofrenia, Família, Enfermagem de Família, Saúde Mental.

\begin{abstract}
Objective: to describe the perception of schizophrenc's about the disease. Methodology: descriptive study a qualitative approach, carried out with five people with medical diagnosis of schizophrenic's in a municipality of Oiapoque. For the production of the data a semi-structured interview, in the domicile was used and analyzed data were analyzed by Iramuteq software. Results: were present the similarity analysis and the six classes generated, the identified categories werw: Patient experience, House routine, Medical routine, Family interaction, Realities of symptoms and Family interaction. Conclusions: The results showed that perceptions are permeated by feelings of despair, such as: frustrations, suffering, loss of quality of life and factors in which family life is difficult, since it is difficult to associate and understand the behaviors resulting from the disease, but the caring concern is the same
\end{abstract}

Key words: Perception, Schizophrenia, Family, Family Nursing, Mental Health.

\section{RESUMEN}

Objetivo: describir la percepción de los familiares de las personas con esquizofrenia acerca de la enfermedad. Metodología: estudio descriptivo de abordaje cualitativo, realizado con cinco familiares de personas con esquizofrenia en el municipio de Oiapoque. Para la producción de los datos se utilizó entrevista semiestructurada y los datos analizados fueron analizados por el software Iramuteq. Resultados: se presentan el análisis de similitud y las seis clases generadas a partir de las percepciones de los familiares: Vivencia con el paciente, Rutina de casa, Rutina médica, Interacción familiar, Realidades de los síntomas e Interacción familiar. Conclusión: Los resultados mostraron que las percepciones que se ha convertido en una de las principales causas de la enfermedad de Chagas, que se ha convertido en una de las causas de la enfermedad.

Palabras clave: Percepción, Esquizofrenia, Familia, Enfermería de Familia, Salud Mental.

1 Universidade Federal do Amapá, Oiapoque-Amapá. *E-mail: fmfernandescb@gmail.com

SUBMETIDO EM: 5/2019

ACEITO EM: 6/2019

PUBLICADO EM: 7/2019 


\section{INTRODUÇÃO}

A esquizofrenia é uma doença caracterizada por prejuízo cognitivo, ou seja, o indivíduo apresenta alterações na atenção, memória, linguagem e funções executivas, causando uma desordem funcional (CRUZ BF, et al., 2010). É uma patologia de curso crônico e de impacto negativo, muitas vezes tornando s indivíduos parcialmente ou completamente inválidos. Acomete principalmente pessoas jovens, geralmente antes dos 25 anos de idade, despertando grande interesse na psiquiatria por ser diversificada, sem escolher raça ou classe social (MAJ M e SANTORIUS N, 2005).

Apesar do considerável avanço em relação à patogênese, ainda não existem exames específicos para confirmar o diagnóstico da esquizofrenia, este por sua vez deve basear-se no quadro clínico, nas manifestações comportamentais e a evolução. Os exames subsidiários servem apenas para estabelecer o diagnóstico diferencial com diversos transtornos (SADOCK BJ e SADOCK VA, 2007). Com relação ao tratamento, este continua a ser um desafio, apesar dos grandes avanços obtidos através de pesquisas acerca desta doença, porém a psicofarmacologia é um grande aliado no processo reabilitativo, principalmente se associado às terapias (FUKUDA IMK, et al, 2008)

Nesse contexto de tratamento e terapias, atualmente existem os Centros de Atenção Psicossocial (CAPS), que possuem um novo caráter de assistência, onde compreendem unidades de atendimento em saúde mental que oferecem aos usuários um programa de cuidados intensivos elaborado por uma equipe multidisciplinar (COIMBRA VCC e KANTORSKI LP, 2005). O CAPS possui um grande significado na inserção do paciente na sociedade além do acompanhamento junto às famílias, preparando-os para enfrentarem a vida social, com respeito e dignidade (BRUM JAM e VESCESLAU RAA, 2014).

Considerando os familiares como parte integrante e fundamental no processo reabilitativo surgiu a inquietação tendo assim como questão norteadora: Qual a percepção dos familiares de pessoas com esquizofrenia acerca da doença, no município de Oiapoque?

Ademais, a partir dos dados encontrados, nas falas dos familiares, espera-se nortear um novo modelo para assistir ao indivíduo, portador de esquizofrenia, juntamente com o núcleo familiar, onde a compreensão dos entes envolvidos no processo de cuidar, façam parte de toda a conjuntura assistencial proporcionando maior autonomia e qualidade de vida aos indivíduos, possibilitando reabilitação social congruente com o seu meio e levando-os ao pleno exercício da cidadania, bem como oriente no planejamento de ações terapêuticas da instituição. Portanto, este estudo objetivou: descrever a percepção dos familiares de pessoas com esquizofrenia acerca da doença.

\section{METODOLOGIA}

Estudo descritivo, com abordagem qualitativa. Participaram do estudo, cinco familiares que convivem diretamente com pessoas que possuem esquizofrenia, com idade igual ou superior a 18 anos e que aceitaram voluntariamente participar do estudo, sendo estes os critérios de inclusão.

O estudo foi realizado em um Centro de Atenção Psicossocial do município de Oiapoque, Estado do Amapá, região norte do Brasil. A coleta de dados ocorreu após leitura e assinatura do Termo de Consentimento Livre e Esclarecido (TCLE), no qual foram marcadas as visitas domiciliares, para realização das entrevistas, a fim de garantir maior privacidade, para que os sujeitos se sentissem mais seguros, facilitando assim o diálogo. A coleta ocorreu nos meses de julho e setembro do ano de 2017.

Para a produção dos dados utilizou-se um roteiro de entrevista semi-estruturada, com questões relacionadas as percepções dos familiares de pessoas com esquizofrenia acerca da doença. A fim de garantir o anonimato, os participantes foram codificados como Suj. 1, Suj. 2 e assim por diante.

Para o processamento dos dados, utilizou-se o software de análise textual IRAMUTEQ (Interface de R pour les Analyses Multidimensionnelles de Textes et de Questionnaires). O IRAMUTEQ é um software gratuito e com fonte aberta, desenvolvido por Pierre Ratinaud e licenciado por GNU GLP (v2), que permite 
análises estatísticas sobre corpus textuais e sobre tabelas indivíduos/palavras (CAMARGO BV e JUSTO AM, 2013). Esse software visa descobrir a informação essencial existente dentro do texto, através da análise estatística textual, quantificando, classificando e correlacionados as informações do texto. O estudo foi aprovado no Comitê de Ética em Pesquisa da Universidade Federal do Amapá, com CAAE: 68577017.1.0000.0003.

\section{RESULTADOS}

A presente pesquisa foi realizada com cinco familiares de pacientes com esquizofrenia. Todas eram do sexo feminino, com idade entre 40 a 68 anos, o estado civil encontrado na pesquisa foi intercalado de casada, união estável e viúva. A naturalidade das participantes foi variada, porém todas residem no município de Oiapoque. A religião predominante é a católica seguida da evangélica. As profissões observadas iam desde trabalhadora autônoma, comerciante, aposentada e do lar. O principal grau de parentesco é a mãe e também participaram irmã e esposa. Percebe-se que o cuidar materno possui vínculo incondicional e predominante (Tabela 1).

Tabela 1 - Dados dos familiares estudados incluídos no estudo e tempo de diagnóstico e tratamento do paciente $(n=5)$.

\begin{tabular}{|c|c|c|c|c|c|c|c|c|c|}
\hline Identificação & Sexo & $\begin{array}{l}\text { ldade } \\
\text { (Anos) }\end{array}$ & Estado civil & Naturalidade & Religião & Profissão & Parentesco & $\begin{array}{l}\text { Tempo de } \\
\text { diagnóstico } \\
\text { (Anos) }\end{array}$ & $\begin{array}{l}\text { Tempo de } \\
\text { tratamento } \\
\text { (Anos) }\end{array}$ \\
\hline$\overline{\text { Sujeito } 01}$ & $F$ & 40 & Casada & Pará & Evangélica & Autônoma & Irmã & 16 & 5 \\
\hline Sujeito 02 & $F$ & 68 & $\begin{array}{l}\text { União } \\
\text { estável }\end{array}$ & Macapá & Católica & Comerciante & Mãe & 15 & 6 \\
\hline Sujeito 03 & $F$ & 54 & Casada & $\begin{array}{l}\text { Minas } \\
\text { Gerais }\end{array}$ & Evangélica & Do lar & Esposa & 29 & 28 \\
\hline $\begin{array}{l}\text { Sujeito } 04 \\
\text { Sujeito } 05\end{array}$ & $\begin{array}{l}F \\
F\end{array}$ & $\begin{array}{l}60 \\
59\end{array}$ & $\begin{array}{l}\text { Viúva } \\
\text { Casada }\end{array}$ & $\begin{array}{l}\text { Oiapoque } \\
\text { Macapá }\end{array}$ & $\begin{array}{l}\text { Católica } \\
\text { Católica }\end{array}$ & $\begin{array}{l}\text { Aposentada } \\
\text { Aposentada }\end{array}$ & $\begin{array}{l}\text { Mãe } \\
\text { Mãe }\end{array}$ & $\begin{array}{l}32 \\
10\end{array}$ & $\begin{array}{l}6 \\
5\end{array}$ \\
\hline
\end{tabular}

Fonte: Fernanda MFCB, Juliana BS, Carlos MSD, Tancredo CBN, 2017.

\section{Análise de similitude}

A análise de similitude é guiada pela teoria dos grafos, ou seja, um modelo matemático ideal para estudar as relações entre objetos discretos de qualquer tipologia, possibilitando identificar as concorrências entre as palavras e seus resultados trazendo indícios de conexão entre as palavras colaborando na identificação da estrutura de representação (Figura 1).

$\mathrm{Na}$ figura 1 estão dispostas as palavras mais frequentes nas falas dos entrevistados, buscando junto a isso classificar os conteúdos das percepções dos familiares de pessoas portadoras de esquizofrenia, e assim foi visto que as palavras que mais se destacaram foram: "não", "ficar", "assim", "só", "estar", "mesmo".

A representação "não" está associada a várias palavras, tais como: "olhar", "porque", "gente", "querer", "falar", "olhar", "chamar", "paciência", "hospital", "passar", "riso", "agora" e outros expressos no modo de perceber a doença como algo negativo, no qual o paciente perde várias de funções e capacidades atrelados a sintomatologia da doença estudada.

A representação "ficar" se atrela as palavras "ruim", "esquizofrênico", "causa", "quase" e "sozinho".

Desta forma e possível perceber que a palavra "só", se liga a palavra "quando", "tomar" e "remédio", o que demonstra que o familiar tende a ter uma obrigação de não deixar o paciente sozinho, e ter a obrigação de alertar o paciente quando a sua hora de tomar seu medicamento, o que retrata que o familiar nem sempre realiza essa tarefa por prazer e sim por obrigação, desta forma, e possível perceber que o mesmo tende a ter uma rejeição quanto a rotina diária de cuidados que o paciente necessita. 
Figura 1 - Gráfico da análise de similitude baseado e construído a partir da teoria dos grafos.

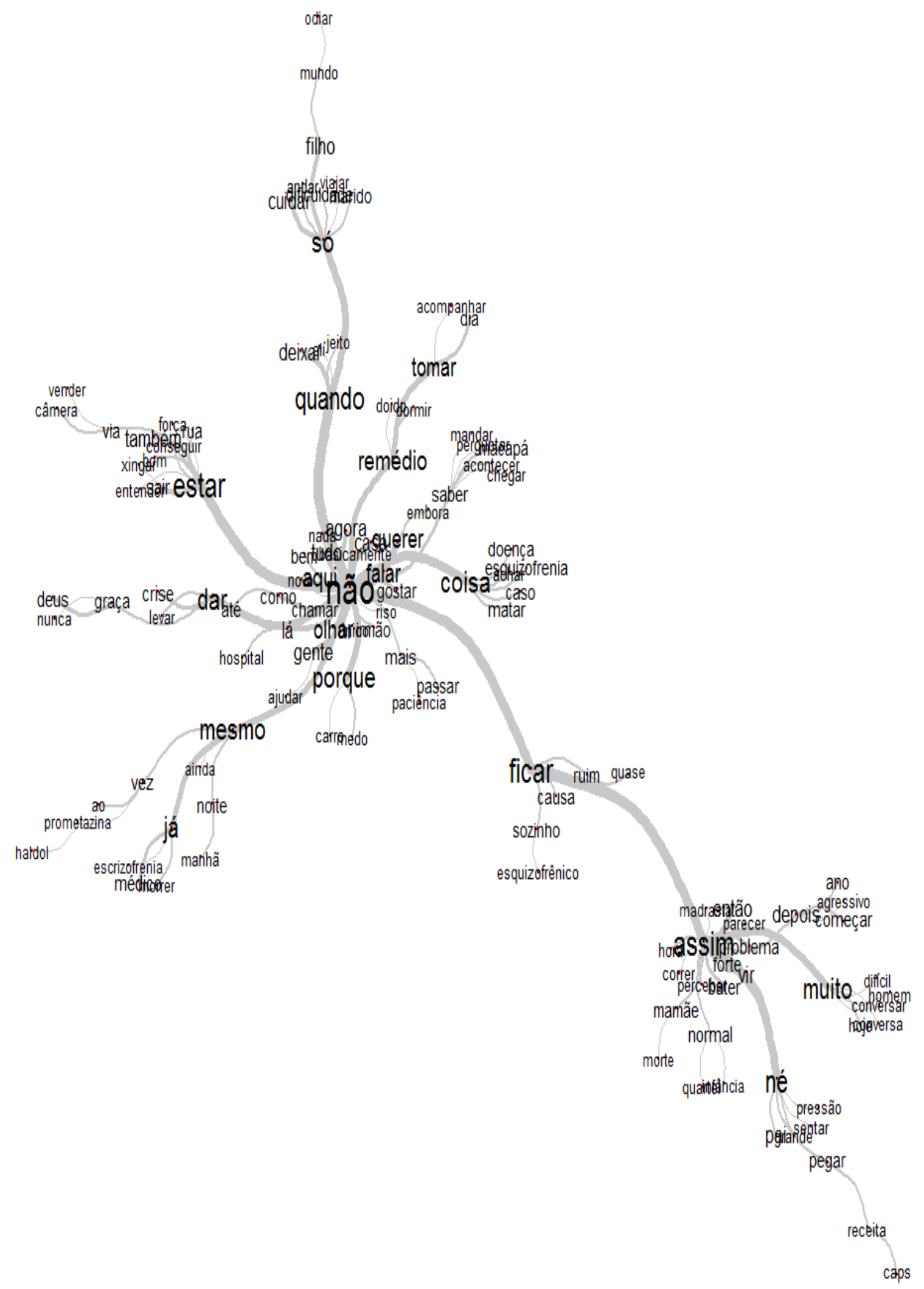

Fonte: IRAMUTEQ, 2017. 
Também se percebe a presença das palavras "estar" e "mesmo", de forma a demonstrar que o familiar deve estar com o paciente o tempo todo, uma vez que esse necessita de atenção e cuidados, o mesmo utilizou-se como uma partícula de confirmação, e de contrariedade, uma vez que durante as entrevistas foi possível perceber que o mesmo era utilizado como marca de contrariedade.

Quando percebemos as palavras "assim", "muito", "né", o possível perceber que o familiar não tende a ter comentários positivos acerca do paciente com esquizofrenia, uma vez que essas palavras demonstram falta de opinião certa acerca da temática, uma vez que quando se cuida de um familiar acometido de uma doença, o cuidado deve ser feito de com atenção e não por obrigação, desta via, é notório que os familiares participantes deste estudo, realizam os cuidados por muitas vezes sem saber a real importância que esse tem para o paciente faltando assim, um pouco de humanização de sua parte, uma vez que este, faz parte de sua família e deve ser tido não como um obrigação mais sim com afeto e zelo.

\section{Análise de segmentos (classes)}

$\mathrm{Na}$ organização de classes das percepções de familiares com pessoas portadoras de esquizofrenia foram reveladas seis classes semânticas, as quais foram geradas a partir do processamento do corpus pelo software IRAMUTEQ que disponibilizou relatório completo e após leitura em profundidade e análise, com base nos discursos dos depoentes, foram nomeadas.

Neste estudo, o software reconheceu a separação do corpus em 04 textos, apesar de terem sido realizadas cinco entrevistas, sendo assim 1 texto automaticamente excluído pelo próprio programa, talvez pela fragilidade do discurso ou excesso de palavras.

O número de formas distintas foi 754 , com número de ocorrências de 3454 . Da amostra de palavras distintas, o software julgou importante e analisou 443, com uma frequência mínima igual ou superior a 3.

Embasado nos dados descritos acima, o programa usou como parâmetro para dividir o corpus em segmentos de texto, classificando-os em função de seus respectivos vocabulários.

Sendo assim, o corpus foi dividido em 82 segmentos de textos analisados de um total de 102, onde teve um nível de aproveitamento de $80,39 \%$ do total do estudo.

A classe 6 teve como destaque as palavras: "aqui", "agora", "saber", "andar", "crise", "receita", assim nos faz pensar numa categoria com nome: Vivência com o paciente. Como pode ser visto nas seguintes falas:

"Olha não foi questão de perceber assim sabe foi na verdade ninguém sabia né aí então ela deu essa crise nela e ela foi levada pra Macapá e lá ela foi diagnosticada a gente veio saber através disso" (Suj.03).

"A dificuldade é que é só eu com eles que cuido aqui, o pai deles já está morto a maior dificuldade é quando aquele ali entra em crise que ele começa a andar" (Suj. 04).

Desta categoria emergem as subcategorias, sendo as palavras da classe 1: "remédio", "hora", "mamãe", "pegar" tendo assim a nomenclatura de: Rotina de casa. O que pode ser observado por meio das falas a seguir:

"Só que ainda hoje ele tem um problema não sai a gente não vê ele sai né não sai e quando ele sai é porque ele tem que ir mesmo no CAPS pegar a receita" (Suj. 02).

"Está pesado só para mim e eu me cuido também porque olha eu tenho problema de pressão alta tenho a diabetes e eu me cuido também né tenho que me cuidar né" (Suj. 05).

Outra subdivisão que aparece na figura acima, como palavras classe 02 compostas pelas palavras "médico", "falar", "muito", "forte", foi denominada de Rotina médica. Conforme explicita os depoimentos abaixo: 
"Ele médico disse que não que é da doença mesmo que ele fala muito nas pessoas que já que já morreram ele fala coisa pessoas o caso da esquizofrenia" (Suj. 01).

"Ela tem esquizofrenia me falaram a médica disse que ela tem está fazendo o acompanhamento com o remédio que ela toma também é só eu que cuido" (Suj. 05).

A classe 5, que possui como destaque as palavras "bem", "pai", "mundo", "depois", nos remete a denominação de Interação familiar. Essas ideias são endossadas pelos relatos a seguir:

"Ele se dá bem com todo mundo com os vizinhos antigamente ele se implicava uma pouco com os vizinhos (risos), mas agora graças a Deus parou porque ele está tomando o medicamento, mas era por causa divido a doença" (Suj. 02).

"Não tem ninguém na família que ela não odeie não tem ninguém ela odeia basicamente todo mundo a filha mais nova dela é uma ela se dá bem com a primeira filha dela a que tem autismo por que ela não fala não briga com ninguém não xinga ninguém" (Suj.03).

Surge a subdivisão da classe 5 em duas classes, sendo a subclasse 4 conforme é possível se verificar no gráfico acima, marcada pelas palavras "só", "via", "filho", "câmera" assim é possível denominar essa classe de Realidade dos sintomas. Conforme se observam nos seguintes relatos:

"Ele já queria já xingar as pessoas na rua porque ele dizia que a pessoa estava seguindo ele já estava nesse ponto já estava com medo já aqui em casa ele dizia que via as câmeras [...] graças a deus ele nunca precisou ser hospitalizado por causa de algum surto" (Suj. 02).

"Eu viajo às pressas com ele que vai bater no hospital só é eu mesmo quando a gente está doente ninguém quer ajudar não [...] ele era normal na infância" (Suj. 04).

A subclasse 3 que apresenta as palavras "tudo", "coisa", "ruim", "saber", pode ser denominada como Impressão familiar. Como observamos pelos relatos:

"Nesse tempo que ele via e imaginava aquelas coisas eu já estava para ficar quase que nem ele porque já estava me deixando ruim oh olha eu já estava ficando era morrendo de medo" (Suj. 02).

"Graças a deus eu nunca cheguei a adoecer para outras pessoas cuidarem deles é deus é quem sabe se caso acontecer alguma coisa comigo" (Suj. 05).

\section{DISCUSSÃO}

A família pode se sentir responsável pelos problemas enfrentados pelo esquizofrênico e, além disso, apresentar ansiedade e insegurança tanto por não saber lidar com alguns comportamentos apresentados, quando sobre a melhor maneira de cuidar do paciente (SOUZA FILHO MD, et al., 2008).

Cuidar de um familiar que possui esquizofrenia modifica a rotina familiar e altera os planos e projetos para o futuro, fazendo com a família comece uma convivência a partir da realidade estabelecida pelo diagnóstico (SILVA IDD e KOCK S, 2015).

A maioria das famílias quando se deparam com a esquizofrenia, sentem-se desprotegidas e notam o impacto da doença no meio familiar, relacionando consequências negativas na presença do familiar adoecido, acumulando tarefas, aumentando despesas, fragilizando as relações sociais, modificando as atividades diárias e se responsabilizando cuidados com o mesmo (ELIOA SC, et al., 2014). Desta forma, cabe aos familiares cuidar do membro familiar afetado, realizar as adaptações na rotina diária, para que 
este familiar possa continuar exercendo suas atividades comuns de vida, com um desgaste menor, melhorando tanto sua própria qualidade de vida quanto a daquele que é cuidado (BARROSO S, BANDEIRA M e NASCIMENTO E, 2009).

Estudos com familiares de pessoas com esquizofrenia mostram os impactos gerado na vida dos familiares, tais como: situações de medo, agressividade, cansaço, estresse e preocupação resultando em desgaste físico e mental, bem como os prejuízos sociais e psíquicos que dificultam o convívio da família com o ser adoecido. Aponta ainda a família como elo fundamental no apoio, acolhimento e recuperação das pessoas com esquizofrenia (CARVALHO CMS et al., 2017)

Assim, o relacionamento familiar torna-se conturbado, na maioria das vezes, pois há mudanças na rotina, associado a negação da situação vivenciada. Entretanto, quando a família assimila a doenças as relações interpessoais tender a se estabilizar. Outro fato que dificulta a vida dos familiares é o preconceito, afastando a família do convívio social antes estabelecido, dificultado a vida social do cuidador (LIMA ICS et al., 2011)

Contudo, outro estudo mostrou que os sentimentos de respeito, empatia e paciência são primordiais e essenciais entre o paciente com esquizofrenia e o cuidador, enfatizando que a comunicação como eixo fundamental no fortalecimento do relacionamento construído ao longo do tempo, destacando a família como peça no tratamento da esquizofrenia (D'ASSUNÇÃO et al., 2016).

No que concerne ao tratamento, família encontra no profissional médico a sua maior fonte de apoio, pois cabe a ele a prescrição dos medicamentos necessários para o controle dos sintomas da esquizofrenia, 0 que é fundamental para que possam conviver com o portador do transtorno mental com tranquilidade (OLIVEIRA RM e FUREGATO ARF, 2012).

Conforme pesquisa realizada sobre tratamento farmacológico em pessoas com esquizofrenia, a medicação é considerada de extrema relevância para o tratamento, sendo indispensável ao controle dos sintomas psicóticos da esquizofrenia. Sabe-se que a utilização de estratégias que combinam medicação e intervenções psicossociais aumenta a possibilidade de recuperação e podem otimizar os resultados, desta foram cabe ao familiar se ocupar com essa rotina de medicação o que gera uma rejeição por parte do familiar ao ter essa "obrigação" (ALVES CRR e SILVA MTA, 2001).

Portanto devido à incapacidade e dificuldade de cuidar de si mesmo produzida pela doença se faz necessário a interação com os familiares, juntamente com um conjunto de suporte social (CORDIOLI AV, 2008). Entretanto a maioria das famílias sentem o impacto da doença no meio familiar e cada pessoa reage de maneira peculiar, sendo a percepção singular a história de vida da família, incluindo as vivências, aprendizagens e desejos (SALES CA et al., 2011).

Ainda nesse contexto, conforme Xavier JM et al. (2012) os familiares têm pouco entendimento a respeito do diagnóstico da doença talvez um processo de informações não repassadas de maneira correta, durante os encontros com os profissionais atuantes, mostrando ainda que que há lacunas no conhecimento sobre o diagnóstico da patologia, o que desperta para a necessidade deste aspecto ser esclarecido durante os encontros entre profissionais, usuários e familiares.

Portanto, as percepções dos familiares acerca das pessoas com esquizofrenia são variadas, outrora permeou a necessidade de uma relação interativa entre a família e o ser adoecido. Nesse sentido, a equipe de saúde necessita trabalhar de forma mais profunda e duradoura essa tríade (doente-família- equipe de saúde). Nessa vertente, se destaca a enfermagem, que exerce um papel fundamental na saúde mental, através de uma visão holística possuindo um amplo conhecimento com fatores precipitados, predisponentes e perpetuantes, tende a realizar cuidados que abrangem os aspectos éticos, culturais, sociais, psicoterápicos, voltado ao paciente, a família e a comunidade.

A Sistematização da Assistência de Enfermagem (SAE) vem tendo um progresso, principalmente na saúde mental, pois a enfermagem sente a necessidade de interagir com o paciente. $O$ processo de enfermagem ao cliente busca o auxílio na modificação do comportamento desejável para que o paciente 
possa se reabilitar ao convívio social. Portanto é de preferencial interesse que a enfermagem assista os pacientes com transtornos esquizofrênicos, e como também sane algumas dúvidas da família a respeito da patologia (PALMA RSF, et al., 2015).

Devem existir intervenções psicossociais que abrangem, além do programa de educação, outras estratégias como, por exemplo, a terapia familiar, têm se apontado eficazes na prevenção de reincididas de pacientes com esquizofrenia, independentemente do uso da medicação. Além do mais, os familiares geralmente aceitam estas intervenções, e têm mostrado eficácia na melhoria da qualidade de vida de toda a família (SCAZUFCA M, 2000).

\section{CONSIDERAÇÕES FINAIS}

O estudo apresenta como limitação, o número de participantes, além do que pelo próprio tipo de estudo, os dados são produzidos pela subjetividade, cujos participantes tem total autonomia para discorrer sobre o que Ihes foi questionado da maneira como percebem e podem se manifestar pela emoção, pelos sentimentos de desvalia que convivem no dia a dia, e, por vezes, desconsideram outros aspectos também vivenciados.

Nesse sentido, entende-se que a família começa a conviver uma realidade diferente, pois manifesta várias dificuldades de como fazer e como cuidar, sabendo pouco sobre a doença. É importante salientar que a família enquanto cuidadora de um ser que possui esquizofrenia, deve-se ter um cuidado especial, mesmo com as dificuldades que possam aparecer, a mesma permaneça unida e fortalecida, proporcionando integridade mental, física e cognitiva do familiar que possui o transtorno mental, lembrandose de oferecer saúde e qualidade de vida.

Contudo, espera-se que este trabalho sirva de incentivo para o meio acadêmico, a sociedade e profissionais da área da saúde, reconhecendo a realidade que a esquizofrenia pode trazer para as famílias e pensem a respeito de sua atuação diária, acolhendo, respeitando à cidadania do portador da esquizofrenia e sua família.

\section{REFERÊNCIAS}

1. ALVES CRR, SILVA MTA. A esquizofrenia e seu tratamento farmacológico. Revista Estudos de Psicologia, PUCCampinas [Internet], 2001; 18 (1): 12-22.

2. BARROSO S, BANDEIRA M, NASCIMENTO E. fatores preditores de sobrecarga subjetiva de familiares de pacientes psiquiátricos atendidos na rede pública de Belo Horizonte, Minas Gerais, Brasil. Caderno de Saúde Pública [Internet], 2009; 25(9): 1957-1968.

3. BRUM JAM, VENCESLAU RAA. Observação sobre o trabalho do enfermeiro em CAPS I na assistência a paciente esquizofrênico. Conhecendo online: Biológicas e Saúde, Santo Antônio de Pádua [Internet], 2014; 1(1): 19-32

4. CAMARGO BV, JUSTO AM. Tutorial para o uso do software de análise textual IRAMUTEQ. Universidade Federal de Santa Catarina: Santa Catarina, 2013.

5. CARVALHO CMS, et al. Vivências de familiares da pessoa com esquizofrenia. Revista Eletrônica Saúde Mental Álcool e Drogas [Internet]; 2017; 13 (3): 125-131.

6. COIMBRA VCC, KANTORSKI LP. O acolhimento em Centro de Atenção Psicossocial. Revista Enfermagem UERJ [Internet], 2005; 13(1): 57-62.

7. CORDIOLI AV. Psicoterapias: Abordagens Atuais. Porto Alegre: Artmed, 2008.

8. CRUZ BF, et al. Associações entre déficits cognitivos e qualidade de vida na esquizofrenia. Revista Psiquiatria Clínica [Internet], 2010; 37(5): 233-239.

9. D'ASSUNÇÃO CF, et al. A enfermagem e o relacionamento com os cuidadores dos portadores de esquizofrenia. Revista Enfermagem Centro Oste Mineiro [Internet], 2016; 1 (6): 2034-2051.

10. ELIOA SC, et al. Sobrecarga do cuidador familiar de pessoas com transtorno mental: uma revisão integrativa. Saúde em Debate [Internet], 2014; 38(103): 996-1007.

11. FUKUDA IMK, et al. Enfermagem Psiquiátrica: em suas dimensões assistenciais. Barueri: Manole, 2008.

12. LIMA ICS et al. Relação do cuidador e da sociedade com a pessoa com esquizofrenia. Revista Pesquisa Cuidado é fundamental (Online). [Internet], 2011; (supl): 84-91. 
13. MAJ M, SANTORIUS N. Esquizofrenia. Trad. Ronaldo Cataldo Costa. 2 ed. Porto Alegre: Artmed, 2005.

14. OLIVEIRA RM, FUREGATO ARF. Um casal de idosos e sua longa convivência com quatro filhos esquizofrênicos. Revista da Escola de Enfermagem da USP [Internet], 2012; 46(3): 618-625.

15. PALMA RSF, et al. Desafios encontrados pelos familiares que convivem com o portador de esquizofrenia. Revista Brasileira de Pesquisa em Ciências da Saúde [Internet], 2015; 2(1): 4-8.

16. SADOCK BJ, SADOCK VA. Compêndio de Psiquiatria: Ciências do Comportamento e Psiquiatria Clínica. Trad. Claudia Dornelles. 9 ed. Porto Alegre: Artmed, 2007.

17. SALES CA, et al. Sentimentos de familiares sobre o futuro de um ser esquizofrênico: perspectivas para o cuidado de enfermagem. Revista Brasileira de Enfermagem [Internet], 2011; 64(3): 551-557.

18. SCAZUFCA M. Abordagem familiar em esquizofrenia. Revista Brasileira de Psiquiatria [Internet], 2000; 22(supl 1): 50-52.

19. SILVA IDD, KOCK S. Esquizofrenia: percepção e vivências do sistema familiar. Revista Psicologia em Foco [Internet], 2015; 7(10): :-18.

20. SOUZA FILHO MD, et al. Avaliação da sobrecarga em familiares cuidadores de pacientes esquizofrênicos adultos. Psicologia em Estudo [Internet], 2010; 15(3): 639-647.

21. XAVIER JM, et al. Percepção dos familiares de pessoas com esquizofrenia acerca da doença. Revista Brasileira em Promoção da Saúde [Internet], 2012; 25(2): 161-166. 